\title{
Long-term outcomes of single-ventricle palliation for unbalanced atrioventricular septal defects: Fontan survivors do better than previously thought
}

\author{
Edward Buratto, MBBS, , ,b,c Xin Tao Ye, BBiomed, ${ }^{\mathrm{a}, \mathrm{b}, \mathrm{c}}$ Gregory King, BBiomed, ${ }^{\mathrm{a}, \mathrm{b}, \mathrm{c}}$ \\ William Y. Shi, MBBS, , ,b,c Robert G. Weintraub, MBBS, ${ }^{\text {b,c,d }}$ Yves d'Udekem, MD, PhD, FRACS, a,b,c \\ Christian P. Brizard, MD, MS, , , b,c and Igor E. Konstantinov, MD, PhD, FRACS ${ }^{a, b, c}$
}

\section{ABSTRACT}

Background: Single-ventricle palliation (SVP) for children with unbalanced atrioventricular septal defect (uAVSD) is thought to carry a poor prognosis, but limited data have been reported.

Methods: We performed a retrospective review of children with uAVSD who underwent SVP at a single institution. Data were obtained from medical records and correspondence with general practitioners and cardiologists.

Results: Between 1976 and 2016, a total of 139 patients underwent SVP for uAVSD. A neonatal palliative procedure was performed in $83.5 \%$ of these patients (116 of 139), and early mortality occurred in $11.2 \%$ (13 of 116). Ninety-four patients underwent stage II palliation, with an early mortality of $6.4 \%$ (6 of 94). Eighty patients $(57.6 \%)$ underwent Fontan completion, with an early mortality of $3.8 \%$ ( 3 of 80 ). Interstage mortality was $11.7 \%$ (12 of 103 ) between stages I and II and 17.0\% (15 of 88) between stage II and Fontan.

Long-term survival was $66.5 \%$ (95\% confidence interval [CI], 57.9\%-73.9\%) at 5 years, $64.4 \%(95 \% \mathrm{CI}, 55.5 \%-72.0 \%)$ at 15 years, and $57.8 \%(95 \% \mathrm{CI}$, $47.5 \%-66.8 \%)$ at 25 years. Survival post-Fontan was $94.9 \%(95 \% \mathrm{CI}$, $86.9 \%-98.0 \%)$ at 5 years, $92.0 \%(95 \%$ CI, $80.6 \%-96.8 \%)$ at 15 years, and $82.4 \%(95 \% \mathrm{CI}, 61.5 \%-92.6 \%)$ at 25 years. Risk factors associated with death or transplantation were aortic atresia (hazard ratio [HR], 5.3; $P=.03$ ) and hypoplastic aortic arch (HR, 2.5; $P=.02)$. Atrioventricular valve operations were required in $31.7 \%$ of the patients (44 of 139), with $31.8 \%$ of them (14 of 44) requiring a further operation.

Conclusions: Children undergoing SVP for uAVSD have substantial mortality, with $<60 \%$ survival at 25 years. However, survival of children who achieve Fontan completion is better than has been reported previously. (J Thorac

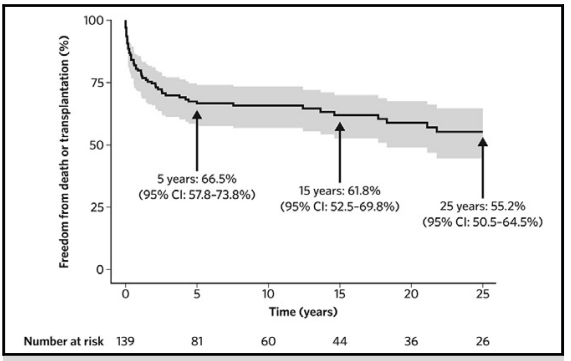

Freedom from death or transplantation for patients with UAVSD undergoing single ventricle palliation.

\section{Central Message}

Patients with unbalanced atrioventricular septal defects who achieve Fontan completion have better survival than was previously thought.

\section{Perspective}

Single ventricle palliation for unbalanced atrioventricular septal defects is associated with substantial mortality, with $<60 \%$ survival at 25 years. However, in those who achieve Fontan completion, survival is similar to that of the general Fontan population. Management of the atrioventricular valve (AVV) remains a challenge, with almost one-third of patients requiring AVV surgery.

See Editorial Commentary page 439. Cardiovasc Surg 2017;153:430-8)

From the Departments of a Cardiac Surgery and dCardiology, Royal Children's Hospital; ${ }^{\mathrm{b}}$ Department of Paediatrics, University of Melbourne; ${ }^{\mathrm{c}}$ Murdoch Children's Research Institute, Melbourne, Australia.

This project was supported by the Victoria Government's Operational Infrastructure Support Program. Dr Buratto is a recipient of a Reg Worcester Scholarship from the Royal Australasian College of Surgeons. Dr d'Udekem is a National Health and Medical Research Council Clinician Practitioner Fellow (1082186).

Read at the 96th Annual Meeting of The American Association for Thoracic Surgery, Baltimore, Md, May 14-18, 2016.

Received for publication May 16, 2016; revisions received Aug 11, 2016; accepted for publication Sept 19, 2016; available ahead of print Oct 28, 2016.

Address for reprints: Igor E. Konstantinov, MD, PhD, FRACS, Royal Children's Hospital, Flemington Rd, Parkville, Victoria 3029, Australia (E-mail: igor.konstantinov@ rch.org.au).

0022-5223/\$36.00

Crown Copyright (C) 2016 Published by Elsevier Inc. on behalf of The American Association for Thoracic Surgery

http://dx.doi.org/10.1016/j.jtcvs.2016.09.051
Children with unbalanced atrioventricular septal defect (uAVSD) constitute approximately $10 \%$ of all patients with atrioventricular septal defect (AVSD). ${ }^{1,2}$ The majority of these children undergo single-ventricle palliation (SVP). Children undergoing SVP for uAVSD have been shown to have a particularly poor prognosis. ${ }^{2-5}$

Scanning this QR code will take you to the article title page. 


\section{Abbreviations and Acronyms \\ AVSD = atrioventricular septal defect \\ $\mathrm{AVV}=$ atrioventricular valve \\ AVVR = atrioventricular valve regurgitation \\ BCPS = bidirectional cavopulmonary shunt \\ HLHS = hypoplastic left heart syndrome \\ $\mathrm{LV}=$ left ventricle \\ PA = pulmonary artery \\ PDA $=$ patent ductus arteriosus \\ SVP = single-ventricle palliation \\ $\mathrm{TAPVD}=$ total anomalous pulmonary venous drainage \\ uAVSD $=$ unbalanced atrioventricular septal defect}

In series published to date, only one-third of patients with uAVSD achieved Fontan completion, and nearly $40 \%$ of those who achieved Fontan completion died by 2.5 years of follow-up. ${ }^{2,3}$ Furthermore, reports on the long-term follow-up of this challenging group of patients are limited. ${ }^{3}$ We retrospectively reviewed our experience of SVP in children with uAVSD.

\section{METHODS}

\section{Patients}

All patients with uAVSD who underwent SVP at the Royal Children's Hospital, Melbourne between January 1, 1976, and January 1, 2016, were included in the study. Ethics approval was granted by the Royal Children's Hospital's Human Research Ethics Committee (HREC 32047E). International patients were excluded, because follow-up data were not available for this group.

Here uAVSD was defined as a complete AVSD, as confirmed on echocardiography, which in the opinion of the treating team was not suitable for biventricular repair (ie, the ventricles could not be septated), owing to either a hypoplastic ventricle or a straddling atrioventricular valve (AVV). Baseline data were collected by retrospective chart review. Follow-up data were obtained by correspondence with the patients' general practitioners and cardiologists. Follow-up was considered complete if the last confirmed patient contact occurred within 2 years of the end of the study period. Early death was defined as death occurring within 30 days after surgery or before discharge from the hospital. Significant AVV regurgitation was defined as moderate or greater AVV regurgitation as assessed on echocardiography.

Stage I palliation was defined as either the Norwood procedure or other procedures. These other procedures included pulmonary artery band, Damus-Kaye-Stansel connection, repair of total anomalous pulmonary venous drainage (TAPVD), ligation of a patent ductus arteriosus (PDA), pulmonary valvuloplasty, or right ventricle-to-pulmonary artery conduit. All Norwood procedures were performed after the year 2000. Stage II procedures were bidirectional cavopulmonary shunt (BCPS) operations. Stage III was Fontan completion.

\section{Statistical Methods}

All data were analyzed using Stata version 13 (StataCorp, College Station, Tex). All continuous data are expressed as mean \pm standard deviation unless specified otherwise. Continuous data were compared between groups using the Mann-Whitney $U$ test. Discrete variables were compared between groups using the $\chi^{2}$ test, unless group size was $<10$, in which case the Fisher exact test was used. Time-dependent endpoints, specifically survival and freedom from death and transplantation, were analyzed using the Kaplan-Meier method, with time commencing at the initial palliation for analysis of the overall cohort and at the individual stages for analyses of each stage of palliation. Risk factors evaluated in a univariable Cox regression were age, moderate or greater atrioventricular valve regurgitation (AVVR), heterotaxy syndrome, double-outlet right ventricle, year of operation (in days since 1976, scaled to years), aortic atresia, aortic arch hypoplasia, hypoplastic pulmonary arteries (PAs), chromosomal abnormality, hypoplastic left ventricle (LV), and Norwood procedure as stage I palliation.

Variables with at least moderate evidence against the null hypothesis $(P<.10)$ were included in a multivariable model. Specifically, for stage I and stage II procedures, a competing risks model was used for survival analysis, where follow-up time was defined as the interval between the relevant stage and last follow-up, death, transplantation, or progression to the next stage. Furthermore, for stage I and II, a competing risks regression was performed with a Fine and Gray proportional subhazards model, using the same univariable predictors and threshold for inclusion in a multivariable model as in the Cox model described above. The threshold for statistical significance was $P<.05$.

\section{RESULTS}

A total of 139 patients underwent SVP for UAVSD at the study institution between January 1, 1976, and January 1, 2016. Follow-up was complete for all patients. The mean follow-up time was $12.2 \pm 14.4$ years (median, 8.4 years; interquartile range [IQR], 1.1-21.1 years). The baseline demographic data are summarized in Table 1. The procedures are summarized in Figure 1.

\section{Stage I Procedures}

Of the 139 children, $16.5 \%$ ( 23 of 139 ) did not undergo a stage I procedure, including $12.2 \%$ (17 of 139) who proceeded directly to stage II and $4.3 \%$ (6 of 139) who proceeded directly to Fontan. The remaining $83.5 \%$ of patients (116 of 139) underwent a stage I procedure (Table 2). The median age at the time of stage I palliation was 11.5 days (IQR, 4.0-63.9 days; mean, $112.8 \pm 378.0$ days). The mean age at stage I was $233.6 \pm 545.7$ days in those operated on before the year 2000 , but decreased to $18.3 \pm 31.8$ days in those operated on from 2000 onward $(P=.002)$. At least one additional concomitant cardiovascular procedure was performed in $50.0 \%$ of the patients (58 of 116). The most common concomitant procedures were PDA ligation $(23.3 \% ; 27$ of 116), PA reconstruction $(8.6 \% ; 10$ of 116$)$, aortic arch repair $(7.8 \% ; 9$ of 116$)$, and TAPVD repair $(6.9 \% ; 8$ of 116). Early mortality was $11.2 \%$ (13 of 116). The Norwood procedure was associated with a significantly greater risk of early mortality compared with other stage I procedures $(45.5 \%$ vs $7.5 \% ; P=.003)$. Early mortality was more frequent in patients who underwent additional concomitant procedures compared with those who did not, but the difference was not statistically significant $(17.2 \%$ vs $5.2 \% ; P=.07)$. Hypoplastic LV $(P=1.0)$, age at time of 
TABLE 1. Demographic data

\begin{tabular}{|c|c|}
\hline Variable & Value \\
\hline Total number of patients & 139 \\
\hline \multicolumn{2}{|l|}{ Sex, n $(\%)$} \\
\hline Male & $79(56.8)$ \\
\hline Female & $60(43.2)$ \\
\hline \multicolumn{2}{|l|}{ Ventricular dominance, $\mathrm{n}(\%)$} \\
\hline Left & $30(21.6)$ \\
\hline Right & $94(67.6)$ \\
\hline Balanced & $15(10.8)$ \\
\hline \multicolumn{2}{|l|}{ Additional cardiac anomalies, $\mathrm{n}(\%)^{*}$} \\
\hline Heterotaxy & $102(73.4)$ \\
\hline DORV & $72(51.8)$ \\
\hline Additional VSD (not inlet) & $69(49.6)$ \\
\hline Bilateral SVC & $59(42.4)$ \\
\hline Right atrial isomerism & $48(34.5)$ \\
\hline Right aortic arch & $45(32.4)$ \\
\hline Secundum ASD & $45(32.4)$ \\
\hline Pulmonary atresia & $43(30.9)$ \\
\hline Interrupted IVC & $41(30.2)$ \\
\hline Left atrial isomerism & $38(27.3)$ \\
\hline TGA & $38(27.3)$ \\
\hline TAPVD & $37(26.6)$ \\
\hline Dextrocardia & $29(20.9)$ \\
\hline Aortic arch hypoplasia & $21(15.1)$ \\
\hline Pulmonary artery hypoplasia & $17(12.2)$ \\
\hline Aortic coarctation & $16(11.5)$ \\
\hline MAPCAs & $8(5.8)$ \\
\hline Aortic atresia & $4(2.9)$ \\
\hline Moderate or greater AVVR at stage $\mathrm{I}, \mathrm{n}(\%)$ & $20(14.4)$ \\
\hline Gastrointestinal malrotation, $\mathrm{n}(\%)$ & $31(23.0)$ \\
\hline Chromosomal abnormality, n (\%) & $11(7.9)$ \\
\hline Trisomy 21 & $4(2.9)$ \\
\hline Other & $7(5.0)$ \\
\hline
\end{tabular}

DORV, Double-outlet right ventricle; $V S D$, ventricular septal defect; $S V C$, superior vena cava; $A S D$, atrial septal defect; $I V C$, inferior vena cava; TGA, transposition of the great arteries; TAPVD, total anomalous pulmonary venous drainage; MAPCAs, major aortopulmonary collateral arteries; $A V V R$, atrioventricular valve regurgitation. *All conditions with more than $2 \%$ of the cohort affected.

operation $(P=.11)$ and surgery before $2000(P=.38)$ were not predictive of early mortality.

Another $11.7 \%$ of patients (12 of 103 ) who survived stage I died before stage II palliation. Age at the time of stage I $(P=.45)$, presence of hypoplastic LV $(P=1.0)$, additional procedures at the time of stage $\mathrm{I}(P=.54)$, and initial surgery before $2000(P=1.0)$ were not significantly predictive of the risk of interstage death.

\section{Stage II Procedures}

A stage II procedure was performed in 94 patients (Table 2). The median patient age at the time of stage II was 10.3 months (IQR, 4.4-20.3 months; mean, $19.2 \pm 32.3$ months), and the median interval between stage I and stage II procedures was 10.7 months (IQR, 3.96-20.4 months; mean, $16.7 \pm 22.7$ months). The mean age at the time of stage II decreased significantly after 2000 (9.5 \pm 9.4 months vs $33.6 \pm 46.1$ months; $P<.001)$. An additional concomitant procedure was performed in $71.3 \%$ of the patients (67 of 94). The most frequently performed concomitant procedures were AVV repair $(13.8 \%$; 13 of 94$)$, TAPVD repair $(12.8 \%$; 12 of 94), main PA division $(12.8 \% ; 12$ of 94$)$, and PA patch enlargement $(9.6 \% ; 9$ of 94$)$. Early mortality was $6.4 \%$ (6 of 94). Moderate or greater AVVR at the time of stage II was associated with increased early mortality $(15.4 \%$ vs $2.9 \% ; P=.048)$. Hypoplastic LV $(P=1.0)$, age at the time of stage II $(P=.13)$, additional concomitant procedures $(P=.18)$, and having undergone initial surgery before $2000(P=.68)$ were not associated with increased risk of early mortality.

Among the patients who survived stage II palliation, another $17.0 \%$ (15 of 88 ) died without progressing to Fontan. Interstage mortality was less frequent after 2000 , but this did not reach statistical significance $(11.3 \%$ vs $25.7 \% ; P=.09)$. Age at the time of stage II $(P=.37)$, hypoplastic LV $(P=.55)$, and additional procedures at the time of stage II $(P=1.0)$ did not predict an increased risk of interstage mortality.

\section{Fontan Procedure}

Eighty patients underwent Fontan completion, the details of which are summarized in Table 2. The median age at the time of Fontan completion was 5.8 years (IQR, 4.3-7.9 years; mean, $7.1 \pm 5.5$ years). The mean age at the time of Fontan has deceased in recent years, from $8.7 \pm 6.9$ years in those who underwent initial surgery before 2000 to $5.2 \pm 2.1$ years in those who underwent initial surgery from 2000 onward $(P=.004)$. Additional procedures were performed in $40.0 \%$ of the patients (32 of 80$)$, most frequently AVV surgery $(15.0 \% ; 12$ of 80$)$ and main pulmonary artery division $(7.5 \% ; 6$ of 80$)$. The median interval between the stage II procedure and Fontan completion was 4.3 years (IQR, 3.5-5.4 years; mean, $4.3 \pm 3.5$ years). Early mortality was $3.8 \%$ ( 3 of 80 ). Age at the time of Fontan $(P=.41)$, hypoplastic LV $(P=.21)$, significant AVVR before Fontan $(P=.45)$, concomitant procedure $(P=.56)$, type of Fontan $(P=1.0)$, and have undergone initial surgery before 2000 $(P=1.0)$ were not predictive of early mortality after Fontan completion.

\section{Survival for the Whole Cohort}

For the overall cohort, survival was $66.5 \%(95 \%$ CI, $57.9 \%-73.9 \%)$ at 5 years, $64.4 \% \quad(95 \% \quad$ CI, $55.5 \%-72.0 \%)$ at 15 years, and $57.8 \% \quad(95 \%$ CI, $47.5 \%-66.8 \%$ ) at 25 years. There were 5 orthotopic cardiac transplantations ( 5 of $139 ; 3.6 \%$ ). Freedom from death and transplantation was $66.5 \%(95 \% \mathrm{CI}, 57.8 \%-73.8 \%)$ at 5 years, $61.8 \%(95 \% \mathrm{CI}, 52.5 \%-69.8 \%)$ at 15 years, and 


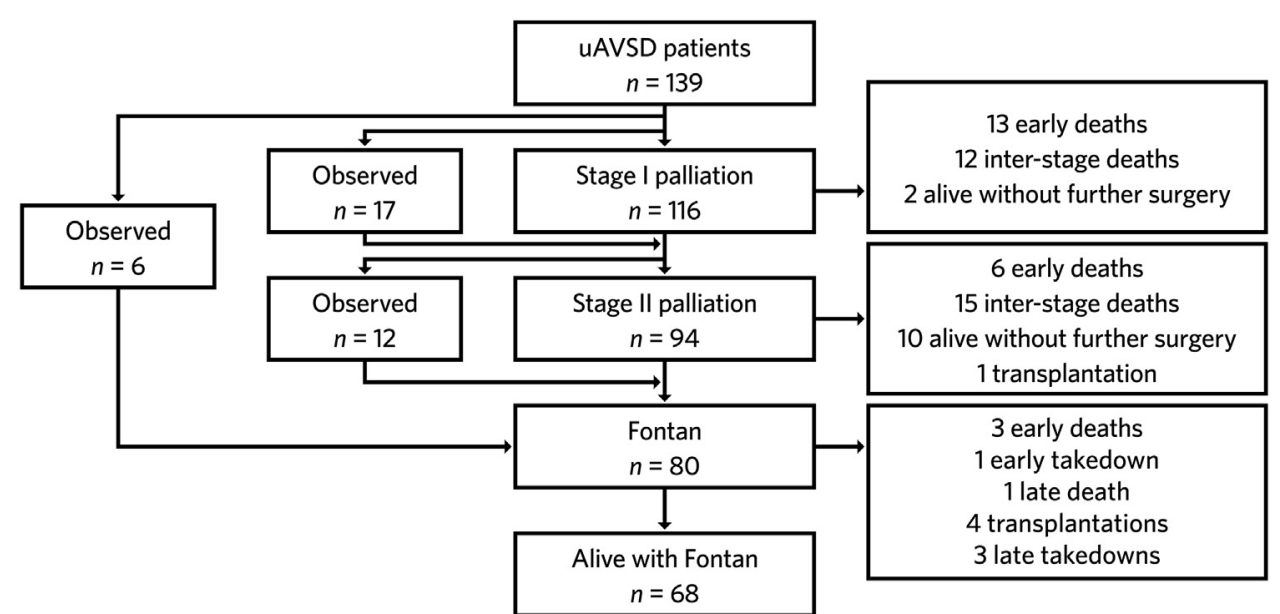

FIGURE 1. Procedures and outcomes.

$55.2 \%(95 \%$ CI, $50.5 \%-64.5 \%)$ at 25 years (Figure $2, A)$. Univariable predictors of death or transplantation are summarized in Table 3. Aortic atresia (HR, 8.5; $P<.001)$, hypoplastic aortic arch (HR, 3.2; $P<.001)$, Norwood procedure (HR, 2.9; $P=.01)$, and more recent initial surgery $(\mathrm{HR}, 1.03 ; P=.04)$ were associated with adverse outcomes. The factors entered into a multivariable model are listed in Table 4. Aortic atresia (HR, 5.3; $P=.03$ )

TABLE 2. Type of procedure and early mortality by stage of palliation

\begin{tabular}{lcc}
\hline \multicolumn{1}{c}{ Procedure } & $\begin{array}{c}\text { Number of } \\
\text { procedures }\end{array}$ & $\begin{array}{c}\text { Early mortality, } \\
\text { n (\%) }\end{array}$ \\
\hline Stage I & 51 & $1(2.0)$ \\
MBT & 28 & $3(10.7)$ \\
Isolated PAB & 13 & $1(7.7)$ \\
Central shunt & 11 & $5(45.5)$ \\
Norwood & 7 & $2(28.6)$ \\
DKS & 2 & $0(0)$ \\
PDA ligation & 1 & $0(0)$ \\
Isolated TAPVD repair & 1 & $1(100)$ \\
RV-PA shunt & 2 & $0(0)$ \\
Pulmonary valvuloplasty & 116 & $13(11.2)$ \\
Total & & \\
Stage II & 41 & $4(9.8)$ \\
BCPS & 31 & $2(6.5)$ \\
Bilateral BCPS & 22 & $0(0.0)$ \\
Kawashima & 94 & $6(6.4)$ \\
Total & & \\
Stage III (Fontan) & 49 & $2(4.1)$ \\
Extracardiac conduit & 21 & $1(4.8)$ \\
Lateral tunnel & 10 & $0(0.0)$ \\
Atriopulmonary connection & 80 & $3(3.8)$ \\
Total & &
\end{tabular}

In cases where more than 1 operation was performed concomitantly, the dominant procedure is listed. $M B T$, Modified Blalock-Taussig shunt; $P A B$, pulmonary artery band; DKS, Damus-Kaye-Stansel connection; $P D A$, patent ductus arteriosus; $T A P V D$, total anomalous pulmonary venous drainage; $R V-P A$, right ventricle to pulmonary artery shunt; BCPS, bidirectional cavopulmonary shunt. and hypoplastic aortic arch (HR, 2.5; $P=.02)$ were independently associated with increased risk of death or transplantation.

\section{Survival Following Stage I}

The competing risk model of outcomes following stage I palliation is shown in Figure 2, $B$. Univariable predictors of death or transplantation are listed in Table 3 . In univariable analysis, aortic arch hypoplasia (HR, 3.1; $P=.01$ ) and Norwood procedure (HR, 3.2; $P=.03$ ) were predictive of death or transplantation, whereas hypoplastic PAs (HR, $0.11 ; P=.03$ ) was predictive of decreased risk. In a multivariable model, significant AVVR at the time of stage I was predictive of decreased transplantation-free survival (HR, $2.5 ; P=.03$ ) (Table 4).

\section{Survival Following Stage II}

The competing risk model of outcomes following stage II palliation is shown in Figure 2, $C$. Univariable predictors of death or transplantation are listed in Table 3. Aortic atresia was associated with increased risk of death or transplantation (HR, 10.6; $P<.001)$. Because no other factors approached statistical significance, multivariable analysis was not performed.

\section{Survival Following Fontan Operation}

The mean follow-up time after Fontan completion was $12.3 \pm 9.7$ years (median, 9.3 years; IQR, 4.2-21.8 years). In the patients who underwent Fontan completion, survival was $94.9 \%(95 \% \mathrm{CI}, 86.9 \%-98.0 \%)$ at 5 years, $92.0 \%$ (95\% CI, 80.6\%-96.8\%) at 15 years, and $82.4 \%(95 \%$ CI, $61.5 \%-92.6 \%)$ at 25 years. Freedom from death, Fontan takedown, and transplantation was $89.7 \%(95 \%$ CI, $80.4 \%-94.7 \%)$ at 5 years, $83.5 \% \quad(95 \% \quad$ CI, $69.7 \%-91.3 \%)$ at 15 years, and $77.3 \% \quad(95 \% \quad \mathrm{CI}$, 


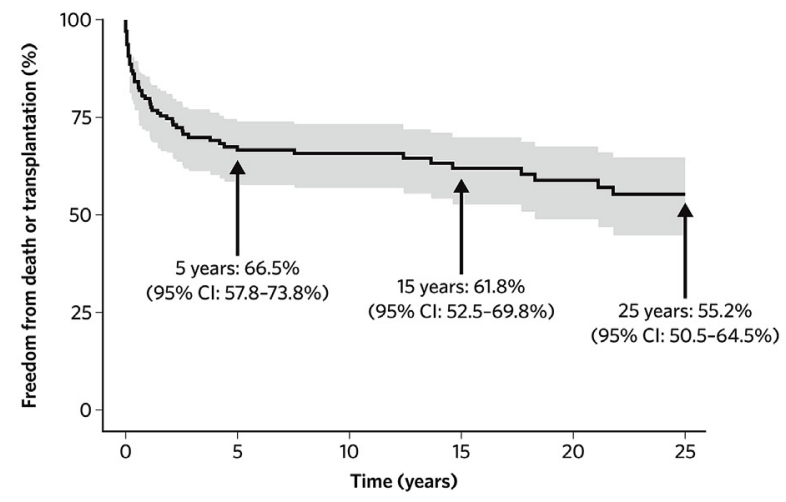

$\begin{array}{llllllll}\text { A Number at risk } & 139 & 81 & 60 & 44 & 36 & 26 & \text { B }\end{array}$

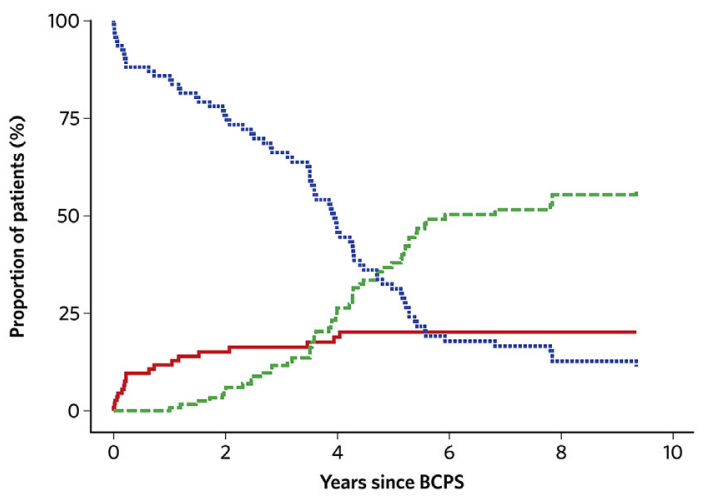

C .......... Alive and awaiting Fontan ----- Progressed to Fontan _- Death

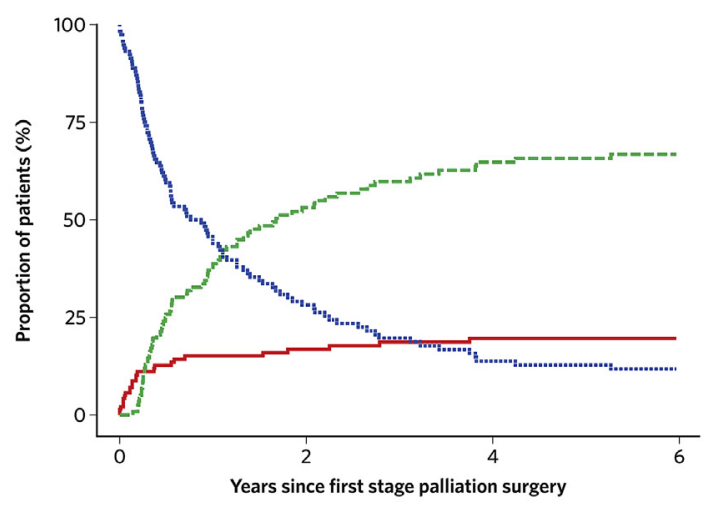

.......... Alive and awaiting BCPS ---= Progressed to BCPS — Death

FIGURE 2. Kaplan-Meier freedom from death and transplantation for the entire cohort (A), competing risk model for stage I (B), competing risk model for stage II (C), and freedom from death, transplantation, and Fontan takedown in patients who underwent Fontan (time in years after Fontan completion) (D). $C I$, Confidence interval; BCPS, bidirectional cavopulmonary shunt.

$57.6 \%-88.6 \%$ ) at 25 years (Figure $2, D$ ). In univariable analysis, only older age at the time of Fontan approached statistical significance as a predictor of death or transplantation (HR, $1.1 ; P=.06$ ). Although chromosomal abnormalities were not predictive of adverse outcome, only 1 of 4 patients $(25 \%)$ with trisomy 21 survived to Fontan.

At the end of the study period, $85.0 \%$ of the patients (68 of 80 ) were alive with a Fontan circulation. Late death occurred in $6.3 \%$ of these patients (5 of 80 ). Fontan takedown was performed in $5.0 \%$ of the patients (4 of 80$), 1$ of whom $(1.3 \%)$ was still alive at last follow-up. Orthotopic cardiac transplantation was performed in 4 patients following the Fontan procedure (4 of $80 ; 5.0 \%), 2$ of whom $(2.5 \%)$ were alive at last follow-up. New York Heart Association (NYHA) functional class could be determined for $97.1 \%$ of the Fontan survivors (66 of 68) at their most recent followup; $83.3 \%$ (55 of 66 ) were in NYHA class I, $12.1 \%(8$ of 66) were in NYHA class II, and 4.5\% (3 of 66) were in NYHA class III. Late complications at the last follow-up included dysrhythmia in $35.0 \%$ (28 of 80 ), hepatic dysfunction in $13.8 \%$ (11 of 80 ), protein-losing enteropathy in $5.0 \%$ (4 of 80 ), and plastic bronchitis in $2.5 \%$ (2 of 80$)$.

\section{AVV Procedures}

Additional procedures on the AVV were performed in $31.7 \%$ of the patients (44 of 139) because of AVVR. Of the initial procedures, $6.8 \%$ ( 3 of 44 ) were replacements, and the remaining $93.2 \%$ (41 of 44 ) were repairs. The timing of the initial AVV procedure based on the stage of palliation is shown in Table 5. Early mortality for initial AVV operations was $18.2 \%$ ( 8 of 44 ). Of those who underwent an AVV operation, 31.8\% (14 of 44) required a second AVV operation, of which $64.3 \%$ (9 of 14) were repairs and $35.7 \%$ (5 of 14 ) were replacements. Another 
TABLE 3. Univariable predictors of death or transplantation for the whole cohort, and each stage of palliation (Fontan take-down is included as failure in the Fontan group)

\begin{tabular}{|c|c|c|c|c|c|c|c|c|}
\hline \multirow[b]{2}{*}{ Variable } & \multicolumn{2}{|c|}{ Whole cohort } & \multicolumn{2}{|c|}{ Stage I } & \multicolumn{2}{|c|}{ Stage II } & \multicolumn{2}{|c|}{ Fontan } \\
\hline & HR $(95 \%$ CI $)$ & $P$ value & HR $(95 \%$ CI $)$ & $P$ value & HR $(95 \%$ CI $)$ & $P$ value & HR $(95 \%$ CI $)$ & $P$ value \\
\hline Age & $1.0(0.95-1.1)$ & .80 & $0.1(0.00-3.6)$ & .20 & $0.94(0.74-1.2)$ & .62 & $1.1(1.0-1.1)$ & .06 \\
\hline Aortic atresia $\dagger$ & $8.5(3.0-24.4)$ & $<.001$ & $3.5(1.3-17.5)$ & .13 & $10.6(4.3-26.3)$ & $<.001$ & $*$ & $*$ \\
\hline Arch hypoplasia & $3.2(1.7-6.0)$ & $<.001$ & $3.1(1.4-7.1)$ & .01 & $1.8(0.59-5.2)$ & .32 & $*$ & $*$ \\
\hline Chromosomal abnormality & $0.88(0.32-2.4)$ & .81 & $0.91(0.21-3.9)$ & .90 & $2.4(0.56-10.6)$ & .24 & $*$ & $*$ \\
\hline DORV & $0.82(0.49-1.4)$ & .64 & $0.56(0.25-1.3)$ & .16 & $1.1(0.47-2.6)$ & .84 & $1.6(0.48-5.3)$ & .46 \\
\hline Heterotaxy & $0.84(0.48-1.5)$ & .55 & $0.78(0.34-1.8)$ & .57 & $0.93(0.33-2.6)$ & .89 & $0.81(0.24-2.7)$ & .73 \\
\hline Hypoplastic LV & $0.92(0.53-1.6)$ & .78 & $1.1(0.47-2.5)$ & .84 & $0.73(0.31-1.7)$ & .48 & $0.95(0.28-3.2)$ & .94 \\
\hline Hypoplastic PAs & $0.62(0.31-1.2)$ & .17 & $0.11(0.01-0.84)$ & .03 & $1.1(0.44-2.8)$ & .83 & $0.85(0.23-3.8)$ & .85 \\
\hline Moderate or greater AVVR & $1.8(0.92-3.5)$ & .09 & $2.5(0.99-6.3)$ & .05 & $1.7(0.72-4.2)$ & .22 & $0.57(0.07-4.5)$ & .59 \\
\hline Norwood procedure & $2.9(1.3-6.5)$ & .01 & $3.2(1.1-9.3)$ & .03 & $1.4(0.32-6.4)$ & .65 & * & $*$ \\
\hline Year of procedure & $1.03(1.0-1.06)$ & .04 & $1.02(0.99-1.1)$ & .15 & $0.97(0.92-1.02)$ & .29 & $0.99(0.92-1.1)$ & .71 \\
\hline
\end{tabular}

Bold indicates the variable reaches statistical significance. $H R$, Hazard ratio; $C I$, confidence interval; $D O R V$, double-outlet right ventricle; $L V$, left ventricle; $P A$, pulmonary artery; $A V V R$, atrioventricular valve regurgitation. *An insufficient number of patients survived to Fontan completion, precluding analysis. $\dagger$ Only 4 patients in total.

$9.1 \%$ of patients ( 4 of 44 ) required a third AVV operation, which included 1 valve closure and 3 re-replacements. No patient required a fourth $\mathrm{AVV}$ operation.

Overall freedom from intervention on the AVV was $72.7 \%(95 \% \mathrm{CI}, 62.7 \%-80.4 \%)$ at 5 years, $63.4 \%(95 \%$ CI, $52.8 \%-72.7 \%)$ at 15 years, and $63.4 \%(95 \% \mathrm{CI}$, $52.8 \%-72.7 \%)$ at 25 years. The risk of undergoing an intervention on the AVV was significantly lower in patients who underwent Fontan completion compared with those who did not (HR, 0.28; $P<.001)$ (Figure 3, A). From the time of Fontan completion, freedom from AVV operation was $95.5 \%(95 \% \mathrm{CI}, 86.7 \%-98.5 \%)$ at 5 years, and remained stable at $92.7 \%(95 \% \mathrm{CI}, 80.8 \%-97.4 \%)$ at 15 and 25 years (Figure 3, B).

\section{DISCUSSION}

Unbalanced AVSD occurs in approximately $10 \%$ of patients with AVSD. ${ }^{1,2}$ A biventricular repair in children with uAVSD might not be feasible owing to either

TABLE 4. Multivariable predictors of death or transplantation

\begin{tabular}{lcc}
\hline Multivariable predictor & HR $(\mathbf{9 5} \% \mathbf{C I})$ & $\boldsymbol{P}$ value \\
\hline Overall & & \\
$\quad$ Aortic atresia & $5.3(1.2-23.0)$ & .03 \\
Aortic arch hypoplasia & $2.5(1.1-5.5)$ & .02 \\
$\geq$ Moderate AVVR & $1.8(0.84-4.0)$ & .13 \\
Year of procedure & $1.0(0.98-1.0)$ & .39 \\
$\quad$ Norwood procedure & $0.82(0.24-2.8)$ & .80 \\
Stage I & & \\
$\geq$ Moderate AVVR & $2.5(1.1-5.9)$ & .03 \\
Hypoplastic PAs & $0.17(0.02-1.3)$ & .09 \\
Aortic arch hypoplasia & $2.1(0.84-5.4)$ & .11 \\
Norwood procedure & $1.8(0.6-5.5)$ & .32 \\
\hline
\end{tabular}

$H R$, Hazard ratio; $C I$, confidence interval; $A V V R$, atrioventricular valve regurgitation; $P A$, pulmonary artery. hypoplasia of 1 ventricle, with or without override of the AVV, or straddling of the subvalvular apparatus, with 2 well-developed ventricles. The outcomes of SVP in children with UAVSD are rarely reported and generally have been poor. ${ }^{2-5}$ Early attempts at Fontan completion in the setting of uAVSD had poor results. ${ }^{4,5}$ More recently, only small series of patients with uAVSD undergoing SVP have been reported. ${ }^{2,3}$

Drinkwater and colleagues ${ }^{2}$ reported 45 patients with uAVSD who underwent SVP between 1986 and 1996. Only 16 of 45 patients $(35.6 \%)$ progressed to Fontan completion. Of the patients who underwent the Fontan operation, $37.5 \%$ (6 of 16 ) had died at a mean follow-up of 2.5 years. More recently, Owens and colleagues ${ }^{3}$ reported 44 patients with uAVSD who presented between 1998 and $2003,79.5 \%$ of whom (35 of 44) underwent SVP. Survival was $51 \%$ at a mean follow-up of 25 months. Only 16 of 44 patients $(36.4 \%$ ) progressed to Fontan completion. The authors did not report the long-term outcomes of patients who survived to Fontan.

In recent large reports of SVP outcomes, the subgroup with uAVSD constituted only a small proportion of the

TABLE 5. Timing of AVV operations in relation to stage of SVP

\begin{tabular}{lc}
\hline \multicolumn{1}{c}{ Stage of SVP } & $\mathbf{n}(\%)$ \\
\hline Total & 44 \\
Before stage I & $1(2.3)$ \\
At the time of stage I & $1(2.3)$ \\
Between stages I and II & $4(9.1)$ \\
At the time of stage II & $17(38.6)$ \\
Between stage II and Fontan & $9(20.4)$ \\
At the time of Fontan & $10(22.7)$ \\
After Fontan & $2(4.5)$ \\
\hline
\end{tabular}

SVP, Single-ventricle palliation. 

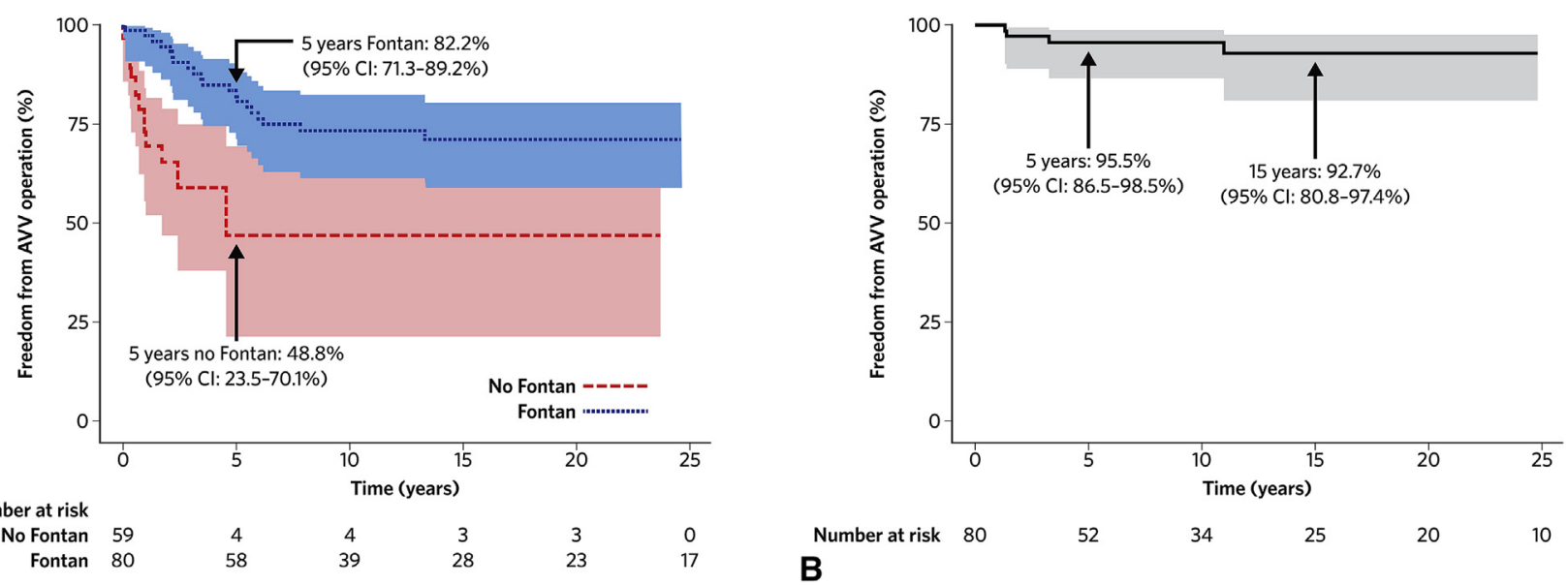

FIGURE 3. Freedom from AVV operation in patients who underwent Fontan and those who did not (A) and freedom from AVV operation after Fontan completion (B). $C I$, Confidence interval; $A V V$, atrioventricular valve.

cohorts. A previous report from our institution described 499 patients who underwent SVP between 1990 and 2008, $14 \%$ of whom (72 of 499) had uAVSD. ${ }^{6}$ Children with uAVSD had worse overall survival and a higher risk of mortality after stage I and stage II procedures in univariable analysis. Rogers and coworkers ${ }^{7}$ reported 771 children who underwent Fontan palliation between 1992 and 2009 , of whom $11.4 \%$ (88 of 771 ) had uAVSD. In multivariable analysis, uAVSD independently predicted death or Fontan takedown within 30 days of operation. Lee and colleagues ${ }^{8}$ reported 557 patients undergoing stage II palliation between 1998 and 2010, of whom 10.2\% had uAVSD. They identified uAVSD as an independent risk factor for failure to achieve Fontan completion. Other recent large reports of Fontan outcomes did not analyze the impact of uAVSD on survival. ${ }^{9-14}$

Overall, there is substantial mortality associated with uAVSD, much of which occurs in the first 5 years, so that only $66.5 \%$ of our patients were alive at 5 years after their first surgery, regardless of the stage of palliative procedure. After this, survival stabilized, with only a minor further decrease to $57.8 \%$ at 25 years. In our patients, aortic arch hypoplasia, and particularly aortic atresia, were independently associated with death or transplantation in multivariable analysis. In univariable analysis, the Norwood operation as the stage I procedure was associated with poorer outcomes, but this lost significance in the multivariable model. This likely occurred because the majority of these patients had aortic atresia or aortic arch hypoplasia, both of which are known risk factors for mortality following the Norwood procedure ${ }^{15,16}$ and were predictors of poor outcome in our multivariable model. Of further interest, LV hypoplasia itself was not associated with poor outcomes in our cohort. In large studies of SVP, hypoplastic left heart syndrome (HLHS) has been associated with significantly poorer outcomes ${ }^{6,7,12}$; however, in patients with hypoplastic LV with aortic atresia or arch hypoplasia, which are known to be higher-risk morphologies of HLHS, ${ }^{15,16}$ survival was indeed worse.

Another point of interest is the high rate of interstage mortality, with $11.7 \%$ of patients dying between stage I and stage II and $17.0 \%$ dying between stage II and Fontan. This is an interesting finding, considering that traditionally the majority of deaths have been thought to occur before BCPS. ${ }^{6}$ The age of our patients at Fontan operation was similar to that reported by other groups. ${ }^{6,9,14}$ Our previous results for the overall Fontan population, ${ }^{6}$ who were of a similar age as our uAVSD cohort, showed a much lower interstage mortality (just over $7 \%$ for both interstage periods). This finding suggests that the risk of interstage death may be specific to patients with uAVSD rather than to the age at which Fontan operation was performed. Furthermore, our findings are consistent with those of Lee and colleagues, ${ }^{8}$ who identified UAVSD as an independent risk factor for failure to progress from stage II palliation to Fontan.

Age at each stage of palliation decreased after the year 2000. After 2000, we tended to perform stage II palliation at the younger age of 3 months to try to minimize interstage mortality, as has been described previously. ${ }^{6}$ Other groups have shown that early BCPS is safe and have advocated its beneficial effects on pulmonary and coronary circulation and in reducing volume load on the systemic ventricle. ${ }^{17,18}$ We did not observe an improvement in survival over time; however, this may reflect the fact that patients with more complex disease underwent surgery in more recent years. For example, all Norwood procedures were performed after 2000, and these patients represent a particularly high-risk group. 
Survival of our patients who achieved Fontan completion was $94.9 \%$ at 5 years and $82.4 \%$ at 25 years. These rates compare favorably with long-term survival in large outcome studies of the Fontan procedure, which reported 20 -year survival of $71 \%$ to $77 \%$ in all patients after Fontan completion. ${ }^{6,11}$ Furthermore, cumulative freedom from death, Fontan takedown, or transplantation was $82.4 \%$ at 15 years after Fontan completion. This finding is consistent with results of recent studies of the entire Fontan population, which found 15-year freedom from Fontan failure in the range of $77 \%$ to $91 \% .^{10,12-14}$ In fact, this is slightly better than the results of the Fontan procedure in patients with HLHS, in whom we previously reported a 10-year freedom from failure of $79 \% .{ }^{6}$ In addition, more than $80 \%$ of Fontan survivors were in NYHA functional class $\mathrm{I}$ at last follow-up. Hirsch and colleagues $^{12}$ also reported that approximately $80 \%$ of survivors in the general Fontan population were in NYHA class I. Thus, outcomes of patients with uAVSD who achieved Fontan completion are not different from those of the general population of patients with Fontan circulation. These results are in contrast to previous reports showing poor outcomes for patients with uAVSD undergoing Fontan..$^{2-5}$

Heterotaxy has been previously described as a risk factor for the Fontan operation. ${ }^{9,19,20}$ Despite the associated challenges, there is evidence of recent improved outcomes in patients with heterotaxy syndrome undergoing the Fontan operation. ${ }^{20,21}$ The majority of our patients $(73 \%$; 102 of 139) had heterotaxy, making it difficult to assess the true impact of heterotaxy per se in patients with uAVSD. Because of the frequent association of heterotaxy and UAVSD, it has been suggested that these 2 factors may interact with each other on multiple regression analysis in these patients. ${ }^{8}$ Indeed, heterotaxy was not a risk factor for adverse outcomes in our patients, likely owing to the fact that the majority of our patients had this.

Surgery on the AVV was performed in nearly one-third of our patients. The operative mortality associated with the initial operation on the AVV was $18.2 \%$, and another approximately one-third of patients underwent reoperation on the AVV. AVVR was previously identified as a risk factor for poor outcomes in SVP. ${ }^{2,6,22,23}$ Owens and coworkers ${ }^{3}$ reported that $30 \%$ of their uAVSD patients required operation for AVVR. They identified undergoing an operation on the AVV as a significant risk factor for death, with $75 \%$ of patients who underwent an AVV operation deceased at a mean follow-up of 25 months. In our cohort, significant AVVR before initial palliation was associated with poorer long-term outcomes. Conversely, significant AVVR at the time of stage II palliation was associated with early death, but not with poorer long-term survival.
This may reflect the fact that few AVV repairs were performed at stage I, when unrepaired AVVR may contribute to late death. Surgery for AVVR was commonly performed at stage II, which might increase surgical risk but may mitigate the risk of late death. These findings are consistent with previous reports indicating that AVVR is a significant risk factor for poor outcomes following stage II. $^{8,24}$ In fact, it has been shown that failure to achieve a successful repair of an AVV with significant regurgitation at the time of stage II is associated with mortality. ${ }^{8}$ In our patients, it appears that the AVV of those who survived to Fontan completion was of better quality, as demonstrated by a lower rate of AVV operations (Figure 3, A). Moreover, it was uncommon for patients to require an AVV operation following Fontan completion (Figure 3,B). Taken together, the foregoing findings emphasize the importance of a competent AVV in patients with UAVSD; however, for those patients with uAVSD and significant AVVR, achieving such competence is particularly challenging.

Unfortunately, simple annuloplasty and "edge-to-edge" repair are often unreliable. ${ }^{25,26}$ In an attempt to address this issue, our group has adopted the "bridging technique" for AVV repair in children with a single ventricle, as described previously. ${ }^{26-28}$ This technique has shown promising early results, but its long-term outcomes remain to be established. ${ }^{25} \mathrm{We}$ are hopeful that this technique can reduce some of the burden associated with AVVR in this cohort.

This study is limited by its retrospective nature. Although this is the largest study of patients with UAVSD who underwent SVP reported to date, our relatively limited sample size precluded further detailed analysis. This might have affected our ability to demonstrate the significance of some postulated risk factors.

\section{CONCLUSIONS}

Children with uAVSD undergoing univentricular repair have high mortality, with $<60 \%$ of patients alive at 25 years after initial palliation. Furthermore, AVVR is a major problem in this group, with nearly one-third of patients requiring AVV surgery, of whom a further one-third required AVV reoperations. However, survival of patients who achieve Fontan completion is better than has been reported previously, and not different from that in the general Fontan population.

\section{Conflict of Interest Statement}

Dr d'Udekem is a consultant for MSD and Actelion. Dr Brizard serves on the advisory board of Admedus. Dr Weintraub serves on the advisory board of Actelion. All other authors have nothing to disclose with regard to commercial support. 


\section{References}

1. Cohen MS, Spray TL. Surgical management of unbalanced atrioventricular canal defect. Semin Thorac Cardiovasc Surg Pediatr Card Surg Annu. 2005;8: 135-44.

2. Drinkwater DC Jr, Laks H. Unbalanced atrioventricular septal defects. Semin Thorac Cardiovasc Surg. 1997;9:21-5.

3. Owens GE, Gomez-Fifer C, Gelehrter S, Owens ST. Outcomes for patients with unbalanced atrioventricular septal defects. Pediatr Cardiol. 2009;30:431-5.

4. Clapp SK, Perry BL, Farooki ZQ, Jackson WL, Karpawich PP, Hakimi M, et al. Surgical and medical results of complete atrioventricular canal: a ten-year review. Am J Cardiol. 1987;59:454-8.

5. Kirklin JW, Blackstone EH, Bargeron LM Jr, Pacifico AD, Kirklin JK. The repair of atrioventricular septal defects in infancy. Int J Cardiol. 1986;13: 333-60.

6. d'Udekem Y, Xu MY, Galati JC, Lu S, Iyengar AJ, Konstantinov IE, et al. Predictors of survival after single-ventricle palliation: the impact of right ventricular dominance. J Am Coll Cardiol. 2012;59:1178-85.

7. Rogers LS, Glatz AC, Ravishankar C, Spray TL, Nicolson SC, Rychik J, et al. 18 years of the Fontan operation at a single institution: results from 771 consecutive patients. J Am Coll Cardiol. 2012;60:1018-25.

8. Lee TM, Aiyagari R, Hirsch JC, Ohye RG, Bove EL, Devaney EJ. Risk factor analysis for second-stage palliation of single ventricle anatomy. Ann Thorac Surg. 2012;93:614-8.

9. Pundi KN, Johnson JN, Dearani JA, Pundi KN, Li Z, Hinck CA, et al. 40-year follow-up after the Fontan operation: long-term outcomes of 1,052 patients. $J$ Am Coll Cardiol. 2015;66:1700-10.

10. Hirsch JC, Goldberg C, Bove EL, Salehian S, Lee T, Ohye RG, et al. Fontan operation in the current era: a 15-year single institution experience. Ann Surg. 2008;248:402-10.

11. Dabal RJ, Kirklin JK, Kukreja M, Brown RN, Cleveland DC, Eddins MC, et al. The modern Fontan operation shows no increase in mortality out to 20 years: a new paradigm. J Thorac Cardiovasc Surg. 2014;148:2517-23.e1.

12. d'Udekem Y, Iyengar AJ, Galati JC, Forsdick V, Weintraub RG, Wheaton GR, et al. Redefining expectations of long-term survival after the Fontan procedure: twenty-five years of follow-up from the entire population of Australia and New Zealand. Circulation. 2014;130(11 Suppl 1):S32-8.

13. Weipert J, Noebauer C, Schreiber C, Kostolny M, Zrenner B, Wacker A, et al. Occurrence and management of atrial arrhythmia after long-term Fontan circulation. J Thorac Cardiovasc Surg. 2004;127:457-64.

14. Giannico S, Hammad F, Amodeo A, Michielon G, Drago F, Turchetta A, et al. Clinical outcome of 193 extracardiac Fontan patients: the first 15 years. J Am Coll Cardiol. 2006;47:2065-73.

15. Vida VL, Bacha EA, Larrazabal A, Gauvreau K, Dorfman AL, Marx G, et al. Surgical outcome of patients with mitral stenosis-aortic atresia variant of hypoplastic left heart syndrome. J Thorac Cardiovasc Surg. 2008;135:339-46.
16. Buratto E, Shi WY, Konstantinov IE. The pearls and perils of settling scores in public. Semin Thorac Cardiovasc Surg. 2016. In press.

17. Petrucci O, Khoury PR, Manning PB, Eghtesady P. Outcomes of the bidirectional Glenn procedure in patients less than 3 months of age. J Thorac Cardiovasc Surg. 2010;139:562-8.

18. Ghanayem NS, Tweddell JS, Hoffman GM, Mussatto K, Jaquiss RD. Optimal timing of the second stage of palliation for hypoplastic left heart syndrome facilitated through home monitoring, and the results of early cavopulmonary anastomosis. Cardiol Young. 2006;16(Suppl 1):61-6.

19. Poh CL, Xu M, Galati JC, Iyengar AJ, Cheung M, Brizard CP, et al. Surgical palliation in patients with a single ventricle and dextrocardia. J Thorac Cardiovasc Surg. 2014;148:1475-80.

20. Bartz PJ, Driscoll DJ, Dearani JA, Puga FJ, Danielson GK, O'Leary PW, et al. Early and late results of the modified Fontan operation for heterotaxy syndrome 30 years of experience in 142 patients. J Am Coll Cardiol. 2006;48: 2301-5.

21. Kim SJ, Kim WH, Lim HG, Lee CH, Lee JY. Improving results of the Fontan procedure in patients with heterotaxy syndrome. Ann Thorac Surg. 2006;82: 1245-51.

22. Wong DJ, Iyengar AJ, Wheaton GR, Ramsay JM, Grigg LE, Horton S, et al. Long-term outcomes after atrioventricular valve operations in patients undergoing single-ventricle palliation. Ann Thorac Surg. 2012; 94:606-13.

23. Liu VJ, Yong MS, d'Udekem Y, Weintraub RG, Praporski S, Brizard CP, et al. Outcomes of atrioventricular valve operation in patients with Fontan circulation. Ann Thorac Surg. 2015;99:1632-8.

24. Friedman KG, Salvin JW, Wypij D, Gurmu Y, Bacha EA, Brown DW, et al. Risk factors for failed staged palliation after bidirectional Glenn in infants who have undergone stage one palliation. Eur J Cardiothorac Surg. 2011;40: 1000-6.

25. Ando M, Takahashi Y. Edge-to-edge repair of common atrioventricular or tricuspid valve in patients with functionally single ventricle. Ann Thorac Surg. 2007;84:1571-6.

26. Sughimoto K, Konstantinov IE, Brizard CP, d'Udekem Y. Polytetrafluoroethylene bridge for atrioventricular valve repair in single-ventricle palliation. $J$ Thorac Cardiovasc Surg. 2015; 149:641-3.

27. Konstantinov IE, Sughimoto K, Brizard CP, d'Udekem Y. Single ventricle: repair of atrioventricular valve using the bridging technique. Multimed Man Cardiothorac Surg. 2015; http://dx.doi.org/10.1093/mmcts/mmv027.

28. Takayama T, Nagata N, Miyairi T, Abe M, Koseni K, Yoshimura Y. Bridging annuloplasty for common atrioventricular valve regurgitation. Ann Thorac Surg. 1995;59:1003-5.

Key Words: Fontan, single-ventricle palliation, unbalanced atrioventricular septal defect 